\title{
ACADEMIC AND QUANTITATIVE LITERACY IN HIGHER EDUCATION: RELATIONSHIP WITH COGNATE SCHOOL-LEAVING SUBJECTS
}

\author{
R. N. Prince* \\ e-mail: Robert.Prince@uct.ac.za / https://orcid.org/0000-0002-8640-799X \\ V. Frith* \\ e-mail: Vera.Frith@uct.ac.za / https://orcid.org/0000-0002-2919-7965 \\ S. Steyn* \\ e-mail: Sanet.Steyn@uct.ac.za / https://orcid.org/0000-0001-8788-8206
}

\author{
A. F. Cliff* \\ e-mail: Alan.Cliff@uct.ac.za / https://orcid.org/0000-0002-0316-2457
}

${ }^{*}$ Centre for Educational Testing for Access and Placement /

Centre for Higher Education Development

University of Cape Town

Cape Town, South Africa

\section{ABSTRACT}

Academic and quantitative literacies (AQL) are essential to success in higher education. These literacies are largely not explicitly taught, but acquired indirectly, mostly through practices in various school subjects. The National Benchmark Tests (NBT) Project assesses students' AQL competencies to assist in identifying students who need support, with placement into appropriate programmes and with curriculum development.

We analyse the performance on the NBT AQL test of students who took the school-leaving examinations in Mathematics, Mathematical Literacy, English Home Language and English First Additional Language. We use the subject choice as a representation of the level of a candidate's quantitative competence and language proficiency respectively, and investigate the relative contributions made by these subject choices to a student's AQL.

Students who paired Mathematics with English as Home Language subject had the statistically significant highest mean AQL score and those who took both English First Additional Language and Mathematical Literacy had the lowest. Language competence has a stronger effect than mathematical competence on AQL.

Students who took the subject combination Mathematics and English Home Language at school are better prepared for the academic demands of higher education than their counterparts who took the alternate subjects. Treating these subjects as equivalent to English Home Language and Mathematics for admissions purposes ignores the differences in preparedness of these students. 
Keywords: academic literacies, quantitative literacy, numeracy, language, higher education, school-leaving examinations, university entrance assessments

\section{INTRODUCTION}

It has been acknowledged that there are significant differences between schooling in the Further Education and Training (FET) phase and higher education in South Africa - a so-called "articulation gap" - which is "manifested in students as a lack of sound foundations for tertiary studies and has a profound effect on students' ability to respond positively to higher education programmes" (Scott, Yeld and Hendry 2007, 42). Research studies have shown that one of the most important aspects of the articulation gap is the mismatch between prospective students' academic literacies and the expectations of higher education in terms of their literacy and numeracy practices (Frith and Prince 2016; Prince and Frith 2017; Cliff 2015; Weideman 2019).

Most higher education institutions have introduced interventions in the form of extended degrees programmes and augmented programmes with foundational courses in recognition of their responsibility to address the articulation gap. The National Benchmark Tests Project assesses prospective students' competencies to assist institutions in identifying students most in need of this extra support (Griesel 2006). This is in accordance with the aim of the project to provide information complementary to the National Senior Certificate (NSC) results to allow for more efficient selection and placement of students into appropriate programmes.

In this article we investigate the academic and quantitative literacies of a large sample of prospective students from across South Africa $(n=40394)$ who have taken the cognate NSC subjects, Mathematics, Mathematical Literacy, English Home Language and English First Additional Language (i.e., English at a less advanced level than what is associated with the home language level). We use the performance on the National Benchmark Academic and Quantitative Literacy (NB AQL) test as a measure of students' readiness for the literacy practices of academic disciplines. The aim is to investigate how prepared students who have taken various combinations of these subjects are and to determine the relative contributions of these selected subjects to a student's academic literacies, both separately and in combination. This analysis adds additional understanding of how the complementary information derived from the NB AQL and the NSC can be used effectively.

Ethical clearance for this research was obtained from our faculty's Research Ethics Committee. To ensure that the research we conduct is ethically sound, prospective students writing the National Benchmark Tests are required to sign consent declaration which gives us permission the use of the data we gather from them - including their results - for research purposes provided as long as anonymity is assured. 


\section{ACADEMIC LITERACIES}

In this article we focus on the two inter-related academic literacies that are assessed in the NB AQL test, namely the language (academic literacy) and numeracy (quantitative literacy) components. Our discussion therefore excludes other academic literacies, such as digital and information literacies. Academic literacy (as assessed in the language-oriented components of the NB AQL test) refers to an individual's ability to successfully "negotiate the demands of academic study in a higher education context, in the medium-of-instruction of that context" (Cliff and Yeld 2006, 20). The quantitative literacy assessment in the NB AQL test is based on the definition of quantitative literacy as

"the ability to manage situations or solve problems in practice, and involves responding to quantitative (mathematical and statistical) information that may be presented verbally, graphically, in tabular or symbolic form; it requires the activation of a range of enabling knowledge, behaviours and processes and it can be observed when it is expressed in the form of a communication, in written, oral or visual mode" (Frith and Prince 2006, 30).

It is clear from this definition that language plays an important role in quantitative literacy and this has been recognised by other authors. According to Steen $(2004,21)$, quantitative literacy refers to the "interpretation, understanding and the power of language". As Barton $(2006,29)$ points out in his research on the commonplace numerical skills used in everyday life, "when people talked of having difficulty with numbers ... the language and literacy associated with numeracy were part of the issue". For this reason we prefer not to treat the language aspects of academic literacy separately from quantitative literacy when studying student competencies (as it is mostly done in the literature), but regard them both as integral and inter-dependent aspects of students' academic literacies.

Given the fundamental role played by language in facilitating the process of learning (Uccelli and Snow 2010; Du Plessis 2017) it is unsurprising that there are quite a few studies that endeavour to investigate the impact of language proficiency and literacy levels across many phases in education (such as Prinsloo 2018) and in different fields of study (Maton 2014; Blackie 2014). It also explains the high level of interest in investigating the role of academic literacy, particularly in the local South African context (Weideman 2019; Fouché, Van Dyk and Butler 2017; Sebolai 2016; Cliff 2015; Van Rooy and Coetzee-Van Rooy 2015; Rambiritch 2013).

There are different descriptions of the skills and subskills that constitute a student's capacity to engage successfully with the demands of academic study in the medium of 
instruction (cf. Van Dyk and Weideman 2004; Weideman, Patterson and Pot 2016). Yeld's work (2001) on language knowledge specifications, the original articulation of a construct of academic literacy (Cliff 2015), and this construct's later incarnations (Cliff and Yeld 2006; National Benchmark Test Project 2018) used for the development of the NB AQL test papers, drew on Bachman and Palmer's (1996) conceptualisation of language knowledge. This divided language knowledge into two categories: organisational knowledge and pragmatic knowledge. These two categories, in turn, could be subdivided: grammatical language knowledge and textual language knowledge relating to organisational knowledge; functional knowledge and sociolinguistic knowledge forming part of pragmatic knowledge. Yeld (2001), Cliff and Yeld (2006) and the National Benchmark Test Project (2018) identified specific skills relating to each of these aspects of language knowledge, including some applications of functional language knowledge that are now more closely associated with quantitative literacy.

In recent decades there has also been a recognition of the importance of quantitative literacy as one of the essential academic literacies, with an extensive international literature on the role of quantitative literacy in higher education (for example, articles in the online journal, Numeracy, of the National Numeracy Network). Steen $(2004,22)$ stressed that "quantitative literacy is ... about challenging college-level settings in which quantitative analysis is intertwined with political, scientific, historical, or artistic contexts. Here QL adds a crucial dimension of rigor and thoughtfulness to many of the issues commonly addressed in undergraduate education."

The conceptualisation of quantitative literacy as practice derives from the academic literacies approach (Chapman and Lee 1990; Street 2005; Street and Baker 2006; Lillis et al. 2015) which conceptualises academic literacies as social practices. Here the term "practice" refers to "habitualised ways, tied to particular times and places, in which people apply resources (material or symbolic) to act together in the world" (Chouliaraki and Fairclough 1999, 21). This take on the concept was originally applied to quantitative literacy by theorists like Street (2000, 2005), Baynham and Baker (2002), Barton (2006) and Kelly, Johnston, and Baynham (2007). This has also been examined by researchers such as Oughton (2018), and Craig and Guzman (2018). If we apply this idea, we could consider academic literacies as social practices instead of thinking of it only as a set of skills that ought to be learned. This would also mean that we can describe the difference between the practices of students entering higher education institutions and the requirements of higher education itself as a mismatch that necessitates action on the part of the sector rather than describing it as a student deficit.

In conceptualising quantitative literacy it is also important to clarify its relationship with mathematics. Hughes-Hallet $(2001,94)$ expressed the importance of this relationship well: 
“... mathematics focuses on climbing the ladder of abstraction, while quantitative literacy clings to context. Mathematics asks students to rise above context, while quantitative literacy asks students to stay in context. Mathematics is about general principles that can be applied in a range of contexts; quantitative literacy is about seeing every context through a quantitative lens."

\section{ACADEMIC LITERACIES ASSESSMENT IN THE NATIONAL BENCHMARK TESTS PROJECT}

The National Benchmark Tests Project was commissioned by Higher Education South Africa (HESA), an organisation which represents South African universities, in response to the need for tests to assess the academic readiness of prospective higher education students. The tests developed for the National Benchmark Tests Project, and introduced in 2005, are criterionreferenced and are "constructed to provide information about the level of a test-taker's performance in relation to clearly defined domains of content and/or behaviours (e.g., reading, writing, mathematics) that requires mastery" (Foxcroft 2006, 9).

The NB Academic and Quantitative Literacy (AQL) test aims to measure the academic literacies proficiency of prospective students. Griesel (2006) provides a detailed description of the construct of this test. The various test forms are developed and reviewed by academics from across the higher education sector and therefore are intended to reflect the expectations of higher education in terms of academic literacies of students entering the system.

The academic literacy component of the NB AQL test covers the ability to identify links and other mechanisms that connect parts of a text; to identify and understand the function of parts of a text; to understand the structure and organisation of arguments; to make distinctions (for example between main ideas and supporting detail); to understand and analyse grammatical and sentence structure; to draw conclusions and apply insights; to understand and work with non-literal language; to recognise difference in text genre, tone and register; and to work out the meaning of words from the context (Cliff and Yeld 2006).

A detailed description of the quantitative literacy component of the NB AQL test is provided by Frith and Prince (2018). Briefly, it is intended to assess students' ability to interpret and reason with quantitative information in contexts that are relevant to various academic disciplines, but do not require any specialist knowledge. The information is presented in a variety of modes, for example tables, texts such as scenarios that are quantitative in nature, charts, graphs and diagrams. Test-writers interpret this information and use it to apply quantitative procedures to do simple calculations and estimations, which may involve more than one step. 


\section{NATIONAL SENIOR CERTIFICATE (NSC) SUBJECTS}

\section{Mathematics and Mathematical Literacy}

All candidates writing the NSC school-leaving examinations must write either the Mathematics or Mathematical Literacy exams. Both these subjects are cognate with quantitative literacy, but differ from it in some significant ways.

The National Curriculum and Assessment Policy Statement (CAPS) document describes Mathematics as:

“... a language that makes use of symbols and notations for describing numerical, geometric and graphical relationships. It is a human activity that involves observing, representing and investigating patterns and quantitative relationships in physical and social phenomena and between mathematical objects themselves.” (Department of Basic Education 2011a, 8).

This document also claims that in studying Mathematics a student should develop the ability to solve problems by forcing them to think critically, logically and creatively, and helping them understand real-world phenomena. This description implies that this subject should contribute to the development of students' quantitative literacy, but in practice the main focus of the subject is on learning the discipline of mathematics itself to enable access to a variety of careers or lay the foundations for study in the mathematical sciences.

Mathematical Literacy is described in the appropriate CAPS document as a subject that will:

“... allow individuals to make sense of, participate in and contribute to the twenty-first century world - a world characterised by numbers, numerically based arguments and data represented and misrepresented in a number of different ways." (Department of Basic Education 2011b, 8).

It states that the competencies that should be developed include reasoning, problem solving, interpretation of information and use of technology. These should be developed while learners address authentic real-life contexts but using only relatively elementary mathematical and statistical knowledge. There is a strong emphasis on using this knowledge in context, which means that this subject is concerned with developing quantitative literacy, but the emphasis is on everyday contexts and not restricted to its use in academic discourse. In general, students who have studied Mathematics will have a higher mathematical competence than their peers who have studied Mathematical Literacy, as the latter only requires the application of elementary mathematical and statistical knowledge.

\section{Languages in the National Senior Certificate (NSC)}

The Curriculum Assessment Policy Statements (CAPS) have separated the language subjects 
into a number of different levels, with the Home Language (HL) and First Additional Language (FAL) levels. These two levels are the most prominent as these subjects are core subjects that are compulsory for all students who write the NSC examinations. This distinction of levels applies to all of the eleven official languages (Afrikaans, English, isiNdebele, isiXhosa, isiZulu, Sepedi, Sesotho, Setswana, siSwati, Tshivenda, Xitsonga). It is compulsory for a student to take at least two language subjects, one at Home Language and one at First Additional Language level, and one of these must be English. In addition, learners have the option of taking some other non-official languages as electives at various levels and any of the official languages at Second Additional Language level (Department of Basic Education 2015). The labels "Home Language" and "First Additional Language" refer to the proficiency levels that students are expected to achieve, and not necessarily to the status of the language in a particular student's life. There are many students for example, who study English at the Home Language level but for whom English is not the language they would claim as their mother tongue or home language (compare numbers in Tables 1 and 2).

The language subjects at Home Language level include not only interpersonal communication skills but also language abilities associated with higher cognitive functions or what Cummins (1979) referred to as cognitive academic language - and these skills play an essential part in enabling them to function in the academic context. Students who study at the First Additional Language level do not necessarily have any knowledge of the language when they start schooling but should be reasonably proficient in both interpersonal communication and cognitive academic language by the end of schooling. Unfortunately, many learners still cannot communicate well in their additional language at this stage (Uys et al. 2007). Thus, we expect that a large proportion of those candidates who took English as their First Additional Language subject may struggle to use English as the medium of instruction when they enter higher education study. This is because most of them will not have used English to this extent or for these purposes before and have not developed sufficient cognitive academic language skills. In addition, many of these students will have learnt mathematics through a language medium that is not their own home language which may have had a negative impact on their learning in this subject (Prince and Frith, 2020; Morgan et al. 2014; Bohlmann and Pretorius 2008; Howie 2003).

\section{THE STRUCTURE, ADMINISTRATION AND SCORING OF THE NB AQL TEST}

The NB AQL test consists of four scored AL sections, two scored QL sections and one trial section. Each test consists of approximately 140 multiple choice items each with four alternative answers. Students are allowed 25 minutes to complete the AL and trial sections and 30 minutes 
for the QL sections. Each form of the test consists of sections focussing on academic literacy (four sections) and quantitative literacy (two sections). The test also contains 20 pre-test piloted items that are excluded from scoring and included only as a trial component in the test. The NB tests are administered at test centres across the country under standardised conditions by specially trained invigilators.

Student responses to the test items are scored as either right or wrong. Using the unidimensional three parameter Item Response Theory (IRT) model, like the one described by Yen and Fitzpatrick (2006), a score in the form of a percentage is generated for each student. To ensure that a candidate's test score is independent of the version of the test that was administered to them, linking and equating methods are applied to the results for different versions of the test. The NB tests have anchor items which allow us to use the Stocking-Lord method (Holland and Dorans 2006) to achieve this.

There are 50 items in the sections of the NB AQL test that are devoted to quantitative literacy. The composition of items used in each test form is aligned with a detailed set of test and item specifications. The specification table (Frith and Prince 2006) developed for the NB AQL test includes set out details such as representation of each the competencies, mathematical and statistical ideas that should be present in each test (described as a proportion of items), as well as requirements regarding levels of cognitive complexity as described in the test construct. Calculations included in the test are limited to simple numbers, such as fractions that can easily be simplified by cancellation, to enable students to complete these tasks without a calculator. In many cases answering the question requires estimation.

The other 75 items in the NB AQL test are devoted to the academic literacy domain. Like the quantitative literacy component, items are selected based on a specification table (Cliff and Yeld 2006, 24-25) that indicates the proportion of items that should primarily measure each of the different abilities defined in the construct. It also specifies the proportion of items that should represent each of the four cognitive levels. This component of the test consists of three 17-item sections that are based on a single text per section, as well as one 24 -item section that consists of decontextualized items.

\section{METHODS}

For this analysis, we analysed the NB AQL test results for students $(n=40394)$ who wrote this test in English in 2018 during their last year at school. The cohort included candidates from across South Africa and was limited to those that later completed their NSC examinations and obtained a bachelor's pass that would allow them to progress to degree study at university. However, not all of them would in fact have entered higher education institutions in 2019. In 
other words, although the sample cohort technically consists of prospective higher education students, we will, in the interest of brevity, refer to all of the candidates as students throughout this article.

We generated a summary of the descriptive statistics and a number of box-and-whisker plots to provide a visual representation of the score distribution of the whole sample, as well as the score distributions for a number of subgroups. The first set of subgroups divided the cohort into groups according to their subject selection from the four school subjects we wanted to analyse. There were graphs for each of the following groups: the students who wrote English at Home Language level; their peers who took English as First Additional Language; the students that were enrolled for Mathematics; and their counterparts who took the alternate subject, Mathematical Literacy. We also identified four mathematics-language subject combination groups - Mathematics and English Home Language; Mathematics and English First Additional Language; Mathematical Literacy and English Home Language; Mathematical Literacy and English First Additional Language - and generated the box-and-whisker plots for each of these groups as well.

In order to test the hypothesis that the that mathematics-language groups had an effect on AQL performance, we performed a one-way ANOVA analysis. Prior to conducting the ANOVA, the assumption of normality and homogeneity of variances was evaluated and determined to be satisfied, as the four groups' distributions were associated with skew and kurtosis less than $|2.0|$ and $|9.0|$ respectively (Schmider et al. 2010). We also used the Tukey honesty significant difference (HSD) test in a post hoc analysis in order to determine whether the differences we observed between the means were significant (at the $5 \%$ significance level).

We used the statistical package R (R Core Team 2019) to conduct our data analysis and to generate graphical representations of the data, we used the R package ggplot2 (Wickham 2016).

\section{RESULTS}

\section{Characteristics of the sample}

Table 1 shows the demographic information of the sample cohort that the students provided when they wrote the NB test. About 61 per cent of the cohort were females and 39 per cent males, which is in keeping with the female to male ratio we generally see in cohorts of NB test writers. Approximately three quarters self-declared themselves as black (African or Coloured) and the majority declared that they did not speak English as their home language. Although English was the largest language group, it represented only about 35 per cent of the total sample. 
Table 1: Demographic characteristics of the students in the sample $(n=40394)$

\begin{tabular}{|c|r|r|}
\hline & Number & $\%$ \\
\hline Male & 15728 & 38.9 \\
\hline Female & 24666 & 61.1 \\
\hline Total & 40394 & 100 \\
\hline Population group & & 66.8 \\
\hline African & 26970 & 10.4 \\
\hline Coloured & 4209 & 8.1 \\
\hline Indian & 3266 & 14.3 \\
\hline White & 5785 & 0.4 \\
\hline Not specified & 164 & 100 \\
\hline Total & 40394 & \\
\hline Home language & & 2.3 \\
\hline Afrikaans & 936 & 34.6 \\
\hline English & 13996 & 0.8 \\
\hline isiNdebele & 305 & 15.4 \\
\hline isiXhosa & 6214 & 13.3 \\
\hline isiZulu & 5373 & 7.6 \\
\hline Sesotho & 3056 & 8.0 \\
\hline Sesotho sa Leboa & 3243 & 5.5 \\
\hline Setswana & 2231 & 2.3 \\
\hline siSwati & 933 & 4.5 \\
\hline Tshivenda & 1804 & 4.6 \\
\hline Xitsonga & 1860 & 1.1 \\
\hline Other & 443 & 100 \\
\hline Total & 40394 & \\
\hline . & & \\
\hline
\end{tabular}

Characteristics of the students in the sample that relate to their education experience are shown in Table 2. Just about 16 per cent of the students wrote NSC Mathematical Literacy and less than a third of these students wrote English First Additional Language, so that those who wrote Mathematical Literacy and English First Additional Language represent only about 5 per cent of the total. In contrast, 84 per cent of the students wrote NSC Mathematics and more than half of these wrote English Home Language.

Table 2: Educational characteristics of the students in the sample $(n=40394)$

\begin{tabular}{|l|r|r|}
\hline & Number & $\%$ \\
\hline NSC Mathematics-language subject group & & \\
\hline Mathematics and English First Additional Language & 14870 & 36.8 \\
\hline Mathematics and English Home Language & 19052 & 47.2 \\
\hline Mathematical Literacy and English First Additional Language & 1940 & 4.8 \\
\hline Mathematical Literacy and English Home Language & 4532 & 11.2 \\
\hline Total & 40394 & 100 \\
\hline
\end{tabular}




\section{Distributions of NB AQL test scores according to NSC subject}

Figure 1 shows distributions of NB AQL test scores according to NSC subject for the sample. It can be seen that in general the students who took English at Home Language (ENH) level performed considerably better on the NB AQL test than those who took English First Additional Language (ENF). It is clear from these scores of the students who wrote NSC Mathematics (MTH) are higher than those of the students who wrote NSC Mathematical Literacy (MTL), showing that, in terms of academic literacy, students who take Mathematics are likely more prepared for the demands of higher education.

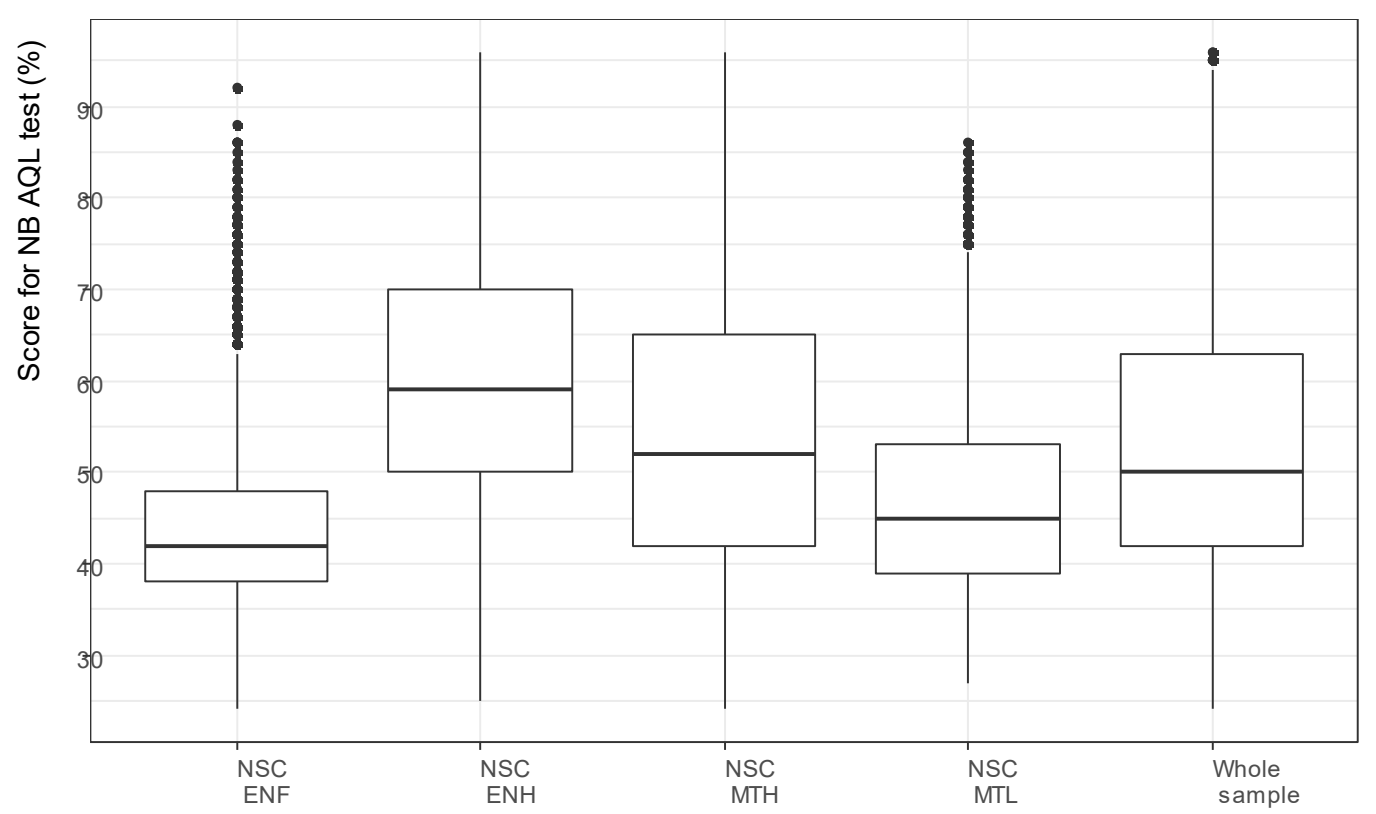

Figure 1: Distributions of scores for the NB AQL test by school subject and for the whole sample (ENF: English First Additional Language; ENH: English Home Language; MTH: Mathematics; MTL: Mathematical Literacy)

\section{Comparison of NB AQL performances of NSC mathematics-language subject combination groups}

As the results discussed in the previous section show, the group of students who have taken the subject combination Mathematical Literacy and English as the First Additional Language subject are the most likely to struggle when required to employ the academic literacy skills associated with higher education. On the other hand, students who are enrolled for Mathematics and English at Home Language level at school are likely better prepared. Further analysis of the data for these student subgroups may give us more insight into the potential impact of mathematics-language subject selection on students' academic literacy competencies (as measured in the NB AQL test). Other studies have in fact looked at the relationship between the academic numeracy - a component of the academic literacy we refer to in this article - of 
students entering higher education and both their mathematical and language ability (Prince and Frith 2020).

The NB AQL test performance of groups defined by mathematics-language subject combinations is presented in Figure 2. Unsurprisingly, the group who took the subject combination Mathematics with English Home Language are the least vulnerable, whilst their peers who selected Mathematical Literacy and took English as their First Additional Language subject (MTL and ENF) are the most likely to struggle when faced with the academic literacy demands of higher education. The median scores of these two groups were 38 per cent for the latter and 62 per cent for the former - a difference of 24 percentage points.

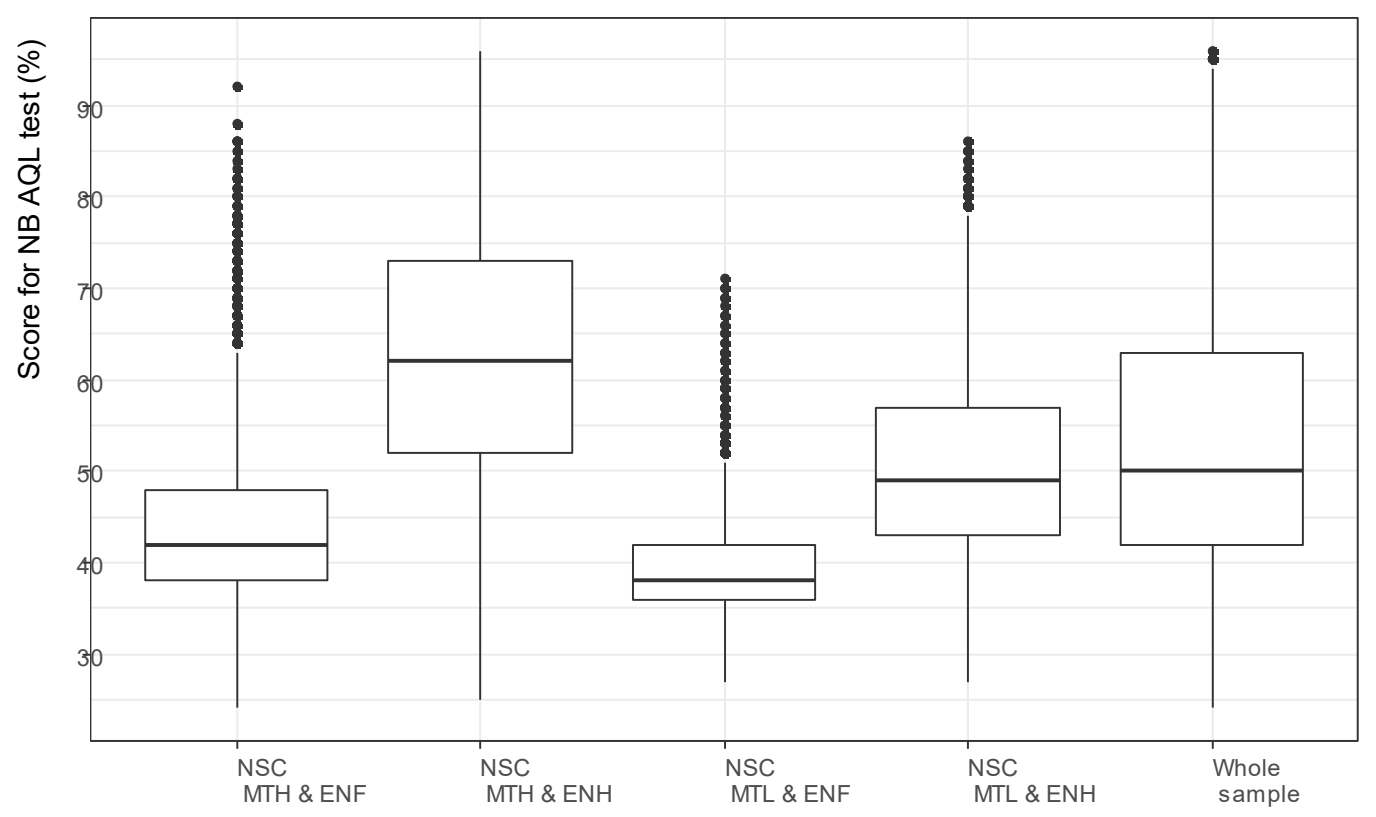

Figure 2: Distributions of scores for the NB AQL test by school subject combination and for the whole sample (MTH and ENF: Mathematics and English First Additional Language; MTH and ENH: Mathematics and English Home Language; MTL and ENF: Mathematical Literacy and English First Additional Language; MTL and ENH: Mathematical Literacy and English Home Language).

By comparing the distributions for the MTL and ENH and MTH and ENH groups in Figure 2, it appears that for students who took English as their Home Language subject, the group that selected of NSC Mathematical Literacy had a lower median NB AQL test score of 49 per cent than their counterparts who selected Mathematics (median of $62 \%$ ), which is quite a large difference in median test score. Comparing the distributions for the MTH and ENF and MTH and ENH groups reveals that for the group that wrote NSC Mathematics, those that selected English as their First Additional Language subject had lower median scores than (median of 42\%) than those that selected English as their Home Language subject (median of $62 \%)$, an even bigger difference in median test score. 
Thus, not having studied English at the Home Language level has only slightly more impact on the average score for the NB AQL than not having studied Mathematics. This suggests that language proficiency and mathematical proficiency are both strongly associated with academic literacy practices.

The descriptive statistics associated with the four mathematics-language subject groups are reported in Table 3. It can be seen that the MTL and ENF group was associated with the numerically smallest mean AQL performance $(M=39.88, S D=5.94)$, followed by MTH and ENF $(M=44.12, S D=8.22)$ and then MTL and ENH $(\mathrm{M}=50.54, S D=9.72)$, and the MTH and ENH group was associated with the numerically highest AQL performance $(M=62.56, S D=13.09)$.

Table 3: Descriptive statistics associated with the four mathematics-language subject groups

\begin{tabular}{|c|c|c|c|c|c|}
\hline & Number & Mean & SD & Skew & Kurtosis \\
\hline \multicolumn{6}{|c|}{ Mathematics-language subject group } \\
\hline $\begin{array}{l}\text { Mathematics and English } \\
\text { First Additional Language }\end{array}$ & 14870 & 44.12 & 8.22 & 1.19 & 1.84 \\
\hline $\begin{array}{l}\text { Mathematics and English } \\
\text { Home Language }\end{array}$ & 19052 & 62.56 & 13.09 & 0.08 & -0.79 \\
\hline $\begin{array}{l}\text { Mathematical Literacy and } \\
\text { English First Additional } \\
\text { Language }\end{array}$ & 1940 & 39.88 & 5.94 & 1.62 & 3.8 \\
\hline $\begin{array}{l}\text { Mathematical Literacy and } \\
\text { English Home Language }\end{array}$ & 4532 & 50.54 & 9.72 & 0.69 & 0.12 \\
\hline
\end{tabular}

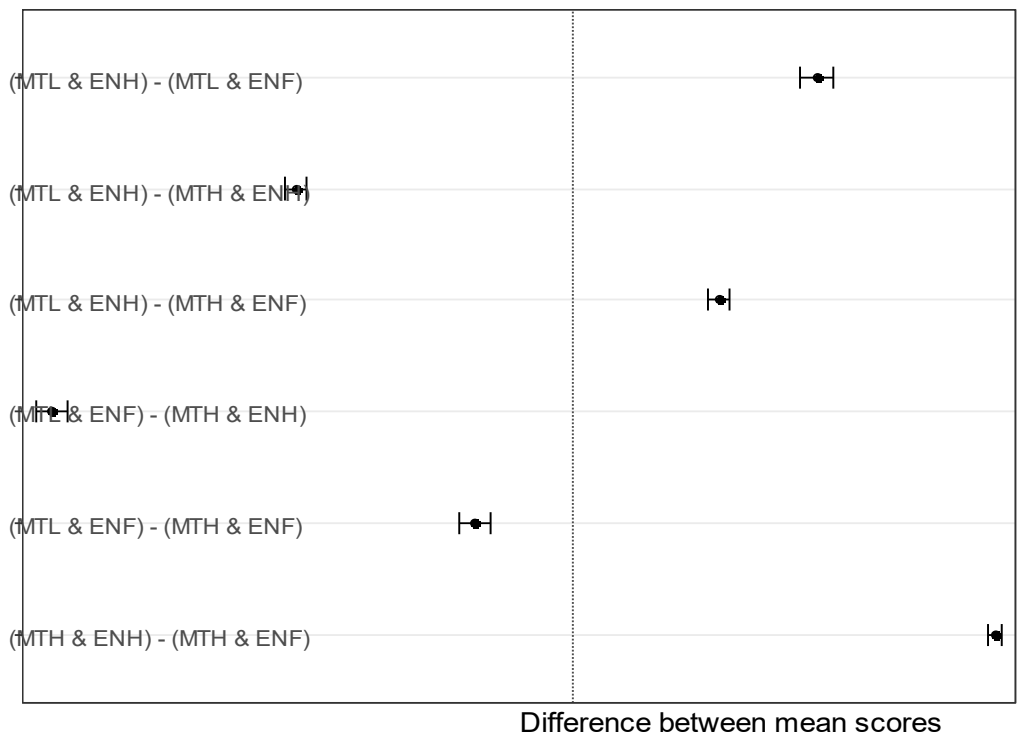

Figure 3: Differences between mean NB AQL test scores for different mathematics-language subject groups with $95 \%$ confidence for the whole sample. None of the confidence intervals contains the value zero (dotted line), indicating that in all cases the difference between the means is significant. (Differences to the left or right of zero are negative or positive respectively) 
The ANOVA analysis showed that the differences between the mean scores for the four mathematics-language subject combination groups are statistically significant at the 5 per cent significance level $[F(3,40390)=9240, p=0.000]$. Post hoc comparisons using the Tukey HSD test showed that there is a significant difference between all six pairs of subject combination groups, as shown in Figure 3. As expected from the differences in the distributions seen in Figure 2 the greatest difference is between the MTL and ENF and MTH and ENH groups and the smallest (though still significant) difference is between MTL and ENH and MTH and ENF groups.

\section{DISCUSSION AND CONCLUSIONS}

Academic and quantitative literacies are essential to success in higher education. However, these literacies are largely not explicitly taught, but rather acquired indirectly, mostly through the practices in various school subjects, but also from practices out of school. This research aims to establish what impact the experience of studying the compulsory school subjects (Mathematics and English Language) at different levels has on students' AQL practices.

This study shows that students who paired Mathematics with English as their Home Language subject had statistically the highest mean AQL score. Those who were enrolled for English Home Language and Mathematical Literacy had the next highest mean AQL score, which indicates that Language competence has the strongest effect on AQL. In general, their peers who took English at First Additional Language level had the lowest AQL scores, while among these students those who took Mathematics fared somewhat better than those who took Mathematical Literacy.

If schooling is to play a more constructive role in preparing students for higher education, attention must be given to developing ways to improve students' AQL practices. On the one hand, it will be important to review the role that the compulsory school subjects play in this development. On the other hand, higher education admission policies need to take into account the differences between the school-leaving subjects and the concomitant AQL competencies of students who have taken them. Currently, scores for English Home Language and First Additional Language are in most cases treated as being equal, and where Mathematics is not explicitly required Mathematics and Mathematical Literacy scores are also treated as being equal. The results of this study show that this approach will lead to the academic literacies challenges experienced by many students not being identified. A similar conclusion was reached by Fleisch, Schoer and Cliff (2015) in a study of the academic language competencies of a cohort of students at one university. Given the results of the current study, it is clear that students who took the subject combination English Home Language and Mathematics at 
school are better prepared to cope with the academic demands of higher education, or at least in terms of the typical academic literacy skills they will need as first-year students. Treating these two subjects as of equal value to English Home Language and Mathematics for admissions purposes implies masking the differences for these students in entry-level literacy preparedness. A further implication is that higher education lecturers may assume a one-sizefits-all approach to teaching and learning practices, which may be inappropriate - even inadequate - to enable students with lower levels of academic literacy to achieve the academic performance outcomes they desire or require for successful study completion.

Given the poor throughput and retention rates of South African higher education it is imperative that teaching and learning challenges, including academic literacies challenges, be addressed. The specifications of the NB AQL test provide a "blueprint" on which the test is constructed (Cliff and Yeld 2006; Frith and Prince 2006) and this blueprint in turn provides insight into both an overall conception of academic and quantitative literacy and the subdomains on which this conception is based. These sub-domains can be utilised by higher education academics as a basis for the design of teaching and learning interventions across disciplinary contexts in higher education.

What the current study and others have shown is that the results students obtain for the NSC subjects do not provide sufficient useful information to assist with identifying the challenges students experience in terms of academic literacies. For example, the differences in academic literacy preparedness between English Home Language and English First Additional Language subject performance are not visible from the school subject scores alone.

This study illustrates how the NB AQL test provides complementary entry-level readiness information that - if understood and utilised appropriately - can assist the higher education sector as a whole, institutions, programmes, courses and students to adapt their teaching and learning practices in order to improve the graduation and retention of students in the system. There has been increasing recognition of the need for more responsive curricula, and our responsiveness, as institutions and educators, to the needs of our students, is perhaps more important now than ever before (Fomunyam and Teferra 2017). Most current curricula predominantly cater to the needs of the "average" student. They would need to be redesigned to move away from this "one size fits all" approach to take the needs and characteristics of the target group into account (Ferdinand 2009; Ogude, Nel and Oosthuizen 2005; Fomunyam and Teferra 2017). The readiness of different students to handle tertiary study in their chosen field can be better understood as a result of insights we gain from analyses such as those presented in this study, coupled with the type of diagnostic information that an instrument such as the NB AQL test provides. Students' NSC results, their level of ability according to the NB AQL 
test and the potential influence of their NSC subject choices as revealed in this article, all contribute to our understanding of the profile of our students, an understanding of which is a prerequisite for designing responsive curricula.

\section{ACKNOWLEDGEMENTS}

We thank the NB tests project team at the Centre for Educational Assessment (CEA), formerly known as the Centre for Educational Testing for Access and Placement (CETAP), at the University of Cape Town for providing us with the opportunity to conduct this research. This research aims to contribute to the NB tests project's objective to investigate, through assessment, the relationship between school-level exit outcomes and proficiencies at entry level.

\section{REFERENCES}

Bachman, L. F. and A. S. Palmer. 1996. Language Testing in Practice. Hong Kong: Oxford University Press.

Barton, D. 2006. "Significance of a social practice view of language, literacy and numeracy." In Adult Literacy Numeracy and Language, ed. L. Tett, M. Hamilton, and Y. Hillier, 21-30. Maidenhead: Open University Press.

Baynham, M. and D. Baker. 2002. “'Practice' in literacy and numeracy research: Multiple perspectives.” Ways of Knowing 2(1): 1-19.

Blackie, M.A.L. 2014. "Creating semantic waves: Using Legitimation Code Theory as a tool to aid the teaching of chemistry." Chemistry Education Research Practice 15: 462 - 469.

Bohlmann, C. and E. Pretorius. 2008. "Relationships between mathematics and literacy: Exploring some underlying factors." Pythagoras 67: 42-55. https://core.ac.uk/download/pdf/29052088.pdf.

Chapman, A. and A. Lee. 1990. "Rethinking literacy and numeracy." Australian Journal of Education 34(3): 277-289. doi:10.1177/000494419003400305.

Chouliaraki, L. and N. Fairclough. 1999. Discourse in late modernity: Rethinking critical discourse analysis. Edinburgh: Edinburgh University Press.

Cliff, A. and N. Yeld. 2006. "Test Domains and Constructs: Academic Literacy." In Access and Entry Level Benchmarks: The national benchmark tests project, ed. by H. Griesel, 19-25. Pretoria: Higher Education South Africa.

Cliff, A. 2015. "The National Benchmark Test in Academic Literacy: how might it be used to support teaching in higher education?" Language Matters 46(1): 3-21.

Craig, J. and L. Guzman. 2018. "Six propositions of a social theory of numeracy: Interpreting an influential theory of literacy." Numeracy 11(2), Article 2. doi:10.5038/1936-4660.11.2.2.

Cummins, J. 1979. Cognitive academic language proficiency, linguistic interdependence, the optimum age question and some other matters. Working Papers on Bilingualism 19: 121-129.

Department of Basic Education. 2011a. National Curriculum Statement (NCS) curriculum and assessment policy statement Grades 10-12 (General). Mathematics. Pretoria: Department of Basic Education.

Department of Basic Education. 2011b. National Curriculum Statement (NCS) curriculum and assessment policy statement Grades 10-12 (General). Mathematical Literacy. Pretoria: Department of Basic Education. 
Department of Basic Education. 2015. National Policy pertaining to the programme and promotion requirements of the National Curriculum Statement Grades $R$ - 12. Pretoria: Department of Basic Education.

Du Plessis, C. L. 2017. "Developing a theoretical rationale for the attainment of greater equivalence of standard in the Grade 12 Home Language exit-level examinations." $\mathrm{PhD}$ thesis, University of the Free State.

Ferdinand, D. S. 2009. Workforce education and development curriculum responsiveness to culturally and internationally diverse graduate students: A mixed methods study. Carbondale: Carbondale Southern Illinois University.

Fleisch, B., V. Schoer and A. Cliff. 2015. "When signals are lost in aggregation: A comparison of language marks and competencies of first-year university students." South African Journal of Higher Education 29(5): 156-178.

Fomunyam, K. and D. Teferra. 2017. "Curriculum responsiveness within the context of decolonisation in South African higher education." Perspectives in Education 35(2): 196-207.

Fouché, I., T. Van Dyk and G. Butler. 2017. “An 'enlightening course that empowers first years'?: A holistic assessment of the impact of a first-year academic literacy course." Journal of English for Academic Purposes 27: 14-30.

Foxcroft, C. 2006. "The Nature of Benchmark Tests." In Access and Entry Level Benchmarks: The national benchmark tests project, ed. H. Griesel, 7-16. Pretoria: Higher Education South Africa. http://www.cetap.uct.ac.za/sites/default/files/image tool/images/216/2006 HESA Access\%20a nd\%20Entry\%20Level\%20Benchmarks.pdf.

Frith, V. and R. Prince. 2006. "Quantitative literacy." In Access and Entry Level Benchmarks: the national benchmark tests project, ed. H. Griesel, 28-34; 47-54. Pretoria: Higher Education South Africa. http://www.cetap.uct.ac.za/sites/default/files/image_tool/images/216/2006_HESA_ Access\%20and\%20Entry\%20Level\%20Benchmarks.pdf. Accessed 22 November 2018.

Frith, V. and R. Prince. 2016. "Quantitative literacy of school leavers aspiring to higher education in South Africa: Lessons from the South African National Benchmark Quantitative Literacy test." South African Journal of Higher Education 30(1): 138-161.

Frith, V. and R. Prince. 2018. "The National Benchmark Quantitative Literacy test for applicants to South African higher education." Numeracy 11(2). doi:10.5038/1936-4660.11.2.3.

Griesel, H. (Ed.). 2006. Access and entry level benchmarks, the National Benchmark Tests Project. Pretoria: Higher Education South Africa. http://www.cetap.uct.ac.za/sites/default/files/image tool/images/216/2006_HESA_Access\%20and\%20Entry\%20Level\%20Benchmarks.pdf. (Accessed 22 November 2018).

Holland, P. W. and N. J. Dorans. 2006. "Linking and equating." In Educational measurement, ed. R. L. Brennan, 187-220. $4^{\text {th }}$ Edition. Westport: Greenwood/Praeger.

Howie, S. J. 2003. "Language and other background factors affecting secondary pupils' performance in Mathematics in South Africa." African Journal of Research in Mathematics, Science and Technology Education 7(1): 1-20. doi:10.1080/10288457.2003.10740545.

Hughes-Hallet, D. 2001. "Achieving numeracy: The challenge of implementation.” In Mathematics and democracy: The case for quantitative literacy, ed. L. A. Steen, 93-98. USA: National council on education and the disciplines. https://www.maa.org/sites/default/files/pdf/QL/ MathAndDemocracy.pdf

Kelly, S., B. Johnston, and M. Baynham. 2007. "The concept of numeracy as social practice." In The adult numeracy handbook. Reframing adult numeracy in Australia, ed. S. Kelly, B. Johnston, and K. Yasukawa, 35-49. Sydney: Adult Literacy and Numeracy Australian Research Consortium.

Lillis, T., K. Harrington, M. R. Lea, and S. Mitchell. 2015. "Introduction." In Working with academic literacies: Case studies toward transformative practice, ed. T. Lillis, K. Harrington, M. Lea and S. Mitchell, 155-162. USA: WAC Clearinghouse/Parlor Press. http://wac.colostate.edu/ books/lillis/ (Accessed 22 November 2018). 
Maton, K. 2014. Knowledge and Knowers: Towards a realist sociology of education. London and New York: Routledge.

Morgan, C., T. Craig, M. Schuette and D. Wagner. 2014. "Language and communication in mathematics education: An overview of research in the field." ZDM Mathematics Education 46: 843-853. doi:10.1007/s11858-014-0624-9.

National Benchmark Test Project. 2018. "Handbook for Item Development and Review Workshops." Unpublished internal document.

Ogude, N., H. Nel. and M. Oosthuizen. 2005. The challenge of curriculum responsiveness in South African higher education. Pretoria: Council on Higher Education.

Oughton, H. M. 2018. "Disrupting dominant discourses: A (re)introduction to social practice theories of adult numeracy." Numeracy 11(1), Article 2. DOI: doi:10.5038/1936-4660.11.1.2.

Prince, R. and V. Frith. 2017. "The quantitative literacy of South African school-leavers who qualify for higher education.” Pythagoras 38(1): 22-35. doi:10.4102/pythagoras.v38i1.355.

Prince, R. and V. Frith, 2020. "An investigation of the relationship between academic numeracy of university students in South Africa and their mathematical and language ability." ZDM 52(3): $433-445$.

Prinsloo, M. 2018. Op-Ed: "The PIRLS debacle - literacy, language and standards in schools in South Africa." The Daily Maverick, 28 March. https://www.dailymaverick.co.za/article/2018-0323-op-ed-the-pirls-debacle-literacy-language-and-standards-in-schools-in-south-africa/.

$\mathrm{R}$ Core Team. 2019. R: A language and environment for statistical computing. $\mathrm{R}$ Foundation for Statistical Computing, Vienna, Austria. https://www.R-project.org/.

Rambiritch, A. 2013. "Validating the test of academic literacy for postgraduate students (TALPS)." Journal for Language Teaching = Ijenali Yekufundzisa Lulwimi $=$ Tydskrif vir Taalonderrig 47(1): 175-193.

Schmider, E., M. Ziegler, E. Danay, L. Beyer, and M. Buhner. 2010. "Is it really robust? Reinvestigating the robustness of ANOVA against violations of the normal distribution assumption." Methodology: European Journal of Research Methods for the Behavioral and Social Sciences 6: 147-151.

Scott, I., N. Yeld and J. Hendry. 2007. Higher Education Monitor No. 6: A Case for improving teaching and learning in South African higher education. Pretoria: The Council on Higher Education. http://www.che.ac.za/sites/default/files/publications/HE Monitor_6 ITLS_Oct2007 0.pdf. (Accessed 22 November 2018).

Sebolai, K. 2016. "Distinguishing between English proficiency and academic literacy in English." Language Matters 47(1): 45-60.

Steen, L. A. 2004. Achieving quantitative literacy: An urgent challenge for higher education. Washington D.C.: The Mathematical Association of America.

Street, B. 2000. "Literacy events and literacy practices: Theory and practice in the New Literacy Studies." In Multilingual literacies: Reading and writing different worlds, ed. M. Martin-Jones and K. Jones, 17-29. Amsterdam: John Benjamins Publishing.

Street, B. 2005. "Applying new literacy studies to numeracy as social practice." In Urban literacy. Communication, identity and learning in development contexts, ed. A Rogers, 87-96. Hamburg: UNESCO Institute for Education.

Street, B. and D. Baker. 2006. "So, what about multimodal numeracies?" In Travel notes from the new literacy studies, ed. K. Pahl and J. Rowsell, 219-233. Clevedon: Multilingual Matters Ltd.

Uccelli, P. and C. Snow. 2010. "A research agenda for educational linguistics." In The handbook of educational linguistics, ed. B. Spolsky and F. M. Hult, 626-642. Chichester, West Sussex: WileyBlackwell.

Uys, M., J. Van der Walt, R. Van den Berg and S. Botha. 2007. "English medium of instruction: A situation analysis." South African Journal of Education 17(1): 69-82. 
Van Dyk, T. and A. Weideman. 2004. "Switching constructs: On the selection of an appropriate blueprint for academic literacy assessment." Journal for Language Teaching = Ijenali Yekufundzisa Lulwimi = Tydskrif vir Taalonderrig, 38(1):1-13.

Van Rooy, B. and S. Coetzee-Van Rooy. 2015. "The language issue and academic performance at a South African University." Southern African Linguistics and Applied Language Studies, 33(1): $31-46$.

Weideman, A. 2019. "Definition and design: Aligning language interventions in education." Stellenbosch Papers in Linguistics Plus (SPiL Plus) 56: 31-46.

Weideman, A., R. Patterson and A. Pot. 2016. "Construct refinement in tests of academic literacy." In Post-admission language assessment of university students, ed. J. Read, 179-196. Switzerland: Springer.

Wickham, H. 2016. ggplot2: Elegant graphics for data analysis. New York: Springer-Verlag.

Yeld, N. 2001. "Equity, assessment and language learning: Key issues for higher education selection and access in South Africa." PhD thesis, University of Cape Town.

Yen, W. M. and A. R. Fitzpatrick. 2006. "Item response theory." In Educational measurement, ed. R. L. Brennan, 111-153. $4^{\text {th }}$ Edition. Westport: Greenwood/Praeger. 